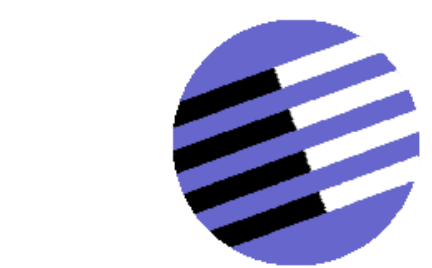

GOVERNANCE AND THE EFFICIENCY

OF ECONOMIC SYSTEMS

GESY

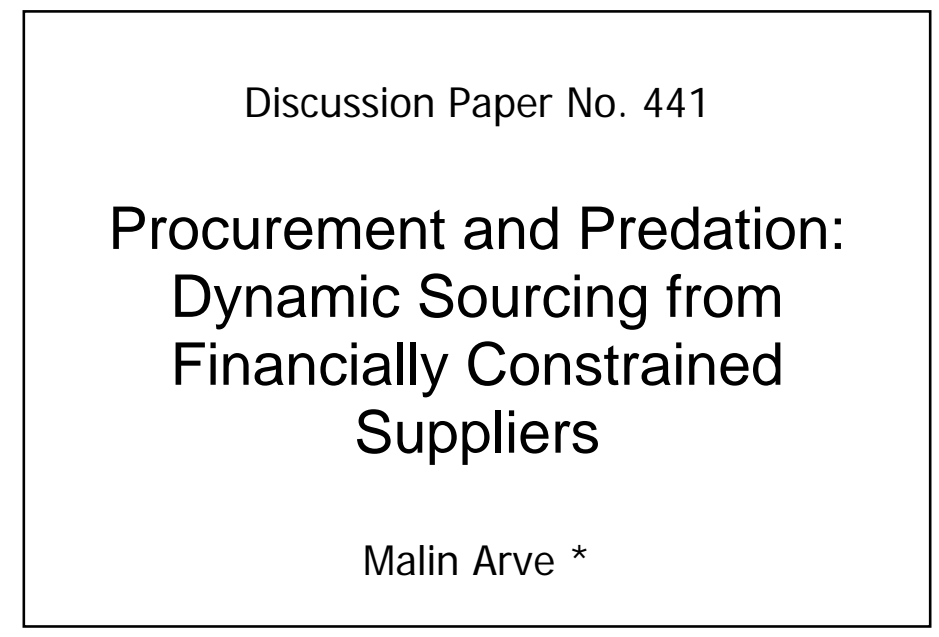

* University of Mannheim

October 2013

Financial support from the Deutsche Forschungsgemeinschaft through SFB/TR 15 is gratefully acknowledged. 


\title{
Procurement and Predation: Dynamic Sourcing from Financially Constrained Suppliers
}

\author{
MALin ARVE*
}

October 30, 2013

\begin{abstract}
This paper studies the interaction between financially constrained and financially strong firms on a procurement market. It characterizes and discusses a procurement agency's optimal response when faced with financially asymmetric firms. By considering a dynamic setting, both present and future consequences and incentives are taken into account.
\end{abstract}

JEL Classification: D82, G30, H57.

Keywords: Asymmetric information, Dual sourcing, Favoritism, Financial constraints, Procurement.

${ }^{*}$ University of Mannheim. E-mail: marve@mail.uni-mannheim.de. Address: University of Mannheim, L7, 3-5, D-68131 Mannheim, Germany. Phone: +49 6211813056. 


\section{Introduction}

The procurement of goods and services such as transport services has an inherent dynamic aspect. When contracting for a service today, the procurer needs to take into account that there will also be a need to (re-)contract for a similar service in the future. This paper takes into account this dynamic aspect of procurement and studies the effects of financial constraints and bankruptcy risk on the optimal procurement contract.

In the case of public transport, a firm needs to make and maintain investments in competence and equipment before being eligible to bid for contracts. This generally keeps the number of bidders low. In late 2008, the Norwegian Health Authority was looking for contractors for medical transport in Finnmark, Norway. The number of bidders was very low and two out of three areas that were up for procurement went to Veolia, a strong player in the Norwegian transport sector, and the last area was contracted out to Loppa Legeskyssbåter, a small, local firm which, because of this contract, survived and ensured future competition in the local market 1 Furthermore, in 2011 in Troms $\varnothing$ in northern Norway, the regional provider, Cominor, lost the competition for bus routes to a large national provider. This loss accounted for about $50 \%$ of the production for Cominor and subsequently led to the firm exiting the local market in Troms $\varnothing 2$

This paper focuses on procurement where the change in the number of competitors is a result of small or financially weak firms leaving the market because they cannot maintain the investment in competence and equipment without the support of external investors 3 In the 2007 Observatory of EU Small and Medium-sized En-

\footnotetext{
${ }_{1}^{1}$ http://www.altaposten.no/lokalt/nyheter/article203130.ece and http://www.helse-finnmark.no/pressemeldinger/ambulansekontrakt-til-loppa-legeskyss baater-article60750-25745.html. Furthermore, Loppa Legeskyssbåter was given a longer contracting period than Veolia in order to ensure "predictability in the competition" (http://www.altaposten.no/lokalt/nyheter/article203131.ece).

${ }^{2}$ http://www.nrk.no/nordnytt/cominor-tapte-anbudet-i-tromso-1.7619509 and http://www.itromso.no/nyheter/trafikk/article451776.ece.

${ }^{3}$ Which for simplicity will be called bankruptcy, but could potentially include exit only from the specific market in question.
} 
terprises (SMEs)4, $21 \%$ of SMEs indicated that accessing finance was a problem 5 In a setting where a small firm faces bankruptcy risk because of its limited access to financial markets, future competition is more likely to be maintained when biasing the procurement design in favor of this firm. However, it is not clear what form such a bias should take and, because biasing is costly, whether this is even optimal. This paper analyzes how and when leveling the playing field between small and big firms in public procurement is optimal. It also contributes to the analysis of the optimality of the US Small Business Act which explicitly favors small firms, and the EU principle of equal treatment across bidders 6

In a two-period setting, the optimal first-period procurement contract exhibits a trade-off between reduced first-period costs by giving the big firm incentives to understate its cost in order to push the small firm out of the market (predation) and increased future competition by favoring the small firm. Second-period procurement always unambiguously favors the small firm by evaluating its cost more leniently than how it would evaluate the same cost announcement by the big firm. This paper further shows that when the procurement agency can either provide funding for the small firm or when the procurement agency can allow the investor to make his contract contingent on the actual realization of the future procurement contract, then the negative spillover effects from the small firm's financial contract disappear and the procurement agency should treat the two firms equally.

The small firm's financing problem makes use of Faure-Grimaud (2000) who shows that an optimal financial contract takes the form of debt contract in which a firm that is not capable of reimbursing a fixed amount faces a risk of bankruptcy. Here this result is applied to the case where profits are endogenously determined by an equilibrium procurement mechanism. That is, if the small firm doesn't perform well enough in the first period, it risks bankruptcy. This gives incentives to the big firm

\footnotetext{
${ }^{4}$ http://ec.europa.eu/enterprise/enterprise_policy/analysis/observatory_en.htm

5 Berger and Udell (2003) and references therein provide evidence of small firms having less access to financial markets than bigger firms.

${ }^{6}$ The US Small Business Act also includes minority- and women-owned businesses, companies located in disadvantaged areas and veteran-owned businesses. However, this paper focuses exclusively on small firms.
} 
to understate its cost so that it can obtain a higher share of the initial market and increase the likelihood of becoming a monopoly provider in the second period. This paper looks at how to strategically design the procurement contract to balance the trade-off between reduced first-period payments by allowing the big firm to behave aggressively to push the small firm out of the market and increased future efficiency and competition by favoring the small firm.

In this paper, although in future procurements (second period), by construction, all active firms are symmetric in terms of financial weakness, the small firm should still receives a larger share of the contract than when the competition is between two financially equal firms. This is because favoring this firm in the second period allows the procurement agency to optimally exploit the big firm's first-period behavior. This paper therefore provides a dynamic optimality rationale for continued favoritism of small firms in auctions. In this sense it differs from previous literature (Branco (1994), Vagstad (1995), and Rezende (2009)) where favoritism stems from the procurement agency having a preference for one of the bidders. Furthermore, this result arises because initial financial asymmetries affect how the procurement agency evaluates firms' bids. The model also allows for cost asymmetries and when the small firm also faces higher costs 7 , then the share of the contract that it gets might further be to its advantage (as in Myerson (1981), McAfee and McMillan (1989), and Maskin and Riley (2000)).

The rest of the paper is organized as follows. The model is presented in Section 2 . Section 3 solves the benchmark procurement contract when firms are not financially constrained. The main results are presented in Section 4 . Finally, Section 5 briefly concludes and discusses the findings.

\section{The model}

- Players and preferences: In period $i, i \in\{1,2\}$, the procurement agency wants to divide the production of an amount $\bar{q}_{i}$ of a certain good between the two firms.

\footnotetext{
${ }^{7}$ Which might justify why the firm is small in the first place.
} 
It enjoys a gross surplus $\bar{S}_{i}$ from the provision of such a service in period $i$.

There are two firms that have the ability to provide the good. However, there is a fixed cost $D>0$ to be paid before the first period 8 Upon payment, this cost is sunk and nonrecoverable. Ex ante the firms differ in that the small firm does not have enough internal funds to self-finance $D$. This firm is therefore called the cash-constrained firm. The big firm does not need external financing to finance the fixed cost $D$ and will for this reason be called the self-financed firm. I.e., the selffinanced firm has a deep pocket and internal funds while the cash-constrained firm has a shallow pocket and needs an investor to finance it in order to participate in the procurement mechanism 9

In each period $i$, a firm $k$ 's cost of procuring the required amount $q$ of the good is $C\left(\theta_{i k}, q\right) \equiv \theta_{i k} q+\frac{\mu}{2} q^{2}$ where $\mu \geq 0.10$ The parameter $\mu$ is industry specific and is therefore common to all firms. Its value is public knowledge. But $\theta_{i k}$ is private information and independent across time and firm:11 and will sometimes be referred to as the firm's type. Furthermore, I allow costs to be drawn from different distributions characterized by the cumulative distribution functions $F_{k}(\cdot)$ with support $\Theta=[\underline{\theta}, \bar{\theta}] .12$ The associated density function is denoted $f_{k}(\cdot)$. Define $\Delta \theta \equiv \bar{\theta}-\underline{\theta}$. It is assumed that the inverse hazard rate $\frac{F_{k}}{f_{k}}$ is increasing. To account for the fact that the small firm may have a lower cost distribution than the big firm, Assumption 1 imposes reverse hazard dominance of $F_{S}$ as in Maskin and Riley

\footnotetext{
${ }^{8} \mathrm{D}$ is a participation cost. It can either be thought of as a cost to invest in the necessary equipment or prototypes to prove that a firm is competent for the task in question or it can be thought of as an administrative cost associated with the bids.

${ }^{9}$ If the self-financed firm is the incumbent and $D$ is an entry cost, then $D$ is already sunk for the self-financed firm and only the cash-constrained firm needs to pay and finance this cost.

${ }^{10}$ The results in this paper hold for a more general cost function $C\left(\theta_{i k}, q\right)$ (see the working paper version of this article).

${ }^{11}$ Because firms differ in their organization, size and style, an economic shock can impact each firm in different ways. For instance, if one firm uses a lot of energy-intensive capital, it will be affected differently by a change in the cost of energy than a firm that relies less on energy-intensive capital. Therefore, depending on the general state of the economy, a firm that is more efficient today, is not necessarily more efficient tomorrow. It is therefore assumed that firms are impacted by idiosyncratic shocks between periods.

${ }^{12}$ In full generality the supports could also differ. However, to alleviate notations the support is the same for the two distributions.
} 
$(2000)$

\section{Assumption 1.}

$$
\frac{F_{C}(\theta)}{f_{C}(\theta)} \leq \frac{F_{S}(\theta)}{f_{S}(\theta)}, \forall \theta \in \Theta
$$

For ease of notation, denote by $\mathrm{C}$ the cash-constrained firm and $\mathrm{S}$ the self-financed firm. Furthermore, define $\theta_{i} \equiv\left(\theta_{i C}, \theta_{i S}\right), i \in\{1,2\}$.

The investment market is assumed to be competitive. Therefore a firm seeking funding has all the bargaining power when it comes to the details of the financial contract 13

Remark: This paper focuses on the case of a sufficiently small $D$. Indeed, if $D$ is large enough, a natural monopoly situation is preferable. This paper focuses on situations where competition is beneficial, but fragile because the small firm is cashconstrained. Of course profits from the procurement stage are endogenous, but in what follows it will be assumed that the (endogenous) expected value of participating in the market is higher than the up-front cost $D$. For instance, ignoring financial asymmetries, $D$ needs to be smaller than $\frac{F_{S}}{f_{S}}(\bar{\theta}) \frac{\bar{q}_{1}+\bar{q}_{2}}{2}$.

Furthermore, it is assumed that $\bar{S}_{i}$ is sufficiently high so that even if there is only one provider, it is optimal to provide $\bar{q}_{i}$. This means that $\bar{S}_{i}>C\left(\bar{\theta}, \bar{q}_{i}\right), i \in\{1,2\}$.

- First-Best Procurement: Without asymmetric information and no financial- or costs constraints, the procurement agency offers a contract $\left\{q_{1 C}\left(\theta_{1}\right), q_{1 S}\left(\theta_{1}\right), t_{1 C}\left(\theta_{1}\right), t_{1 S}\left(\theta_{1}\right)\right.$, $\left.\left\{q_{2 C}\left(\theta_{2}\right), q_{2 S}\left(\theta_{2}\right), t_{2 C}\left(\theta_{2}\right), t_{2 S}\left(\theta_{2}\right)\right\}\right\}$ that solves the following optimization problem 14

$$
\max _{\left(t_{i k}(\cdot), q_{i k}(\cdot)\right)_{i=1,2, k=C, S}} E_{\theta_{1}, \theta_{2}}\left[\sum_{i=1,2}\left(\bar{S}_{i}-t_{i C}\left(\theta_{i}\right)-t_{i S}\left(\theta_{i}\right)\right)\right]
$$

\footnotetext{
${ }^{13}$ As pointed out in Faure-Grimaud (1997) in the opposite case, when the investor has all the bargaining power, the optimal financial contract remains the qualitatively same.

${ }^{14}$ In full generality, second-period variables should also depend on $\theta_{1}$. With independence of costs across periods this will not be the case for the optimal contract. To simplify notations, this contingency is therefore ignored and will also be ignored in the rest of the exposition.
} 
subject to

$$
\begin{aligned}
\Pi_{i k}\left(\theta_{i}\right) & =t_{i k}\left(\theta_{i}\right)-C\left(\theta_{i k}, q_{i k}\left(\theta_{i}\right)\right) \geq 0, \\
q_{i S}\left(\theta_{i}\right) & =\bar{q}_{i}-q_{i C}\left(\theta_{i}\right),
\end{aligned}
$$

where $i \in\{1,2\}, k \in\{C, S\}$.

Observe that since gross surplus is constant, maximizing expected intertemporal net surplus amounts to minimizing expected total cost. Note also that in this paper the procurement agency is constrained to offer only contracts that yields positive profits for each period's procurement 15

It is straightforward to check that without asymmetric information and no financial constraints, productive efficiency requires that whenever possible each firm produces at the same marginal cost 16 Formally $q_{i C}\left(\theta_{i}\right)$ is such that

$$
M C\left(\theta_{i C}, q_{i C}\left(\theta_{i}\right)\right)=M C\left(\theta_{i S}, \bar{q}_{i}-q_{i C}\left(\theta_{i}\right)\right)
$$

where $M C\left(\theta_{i k}, q\right) \equiv \frac{\partial C\left(\theta_{i k}, q\right)}{\partial q}, k \in\{C, S\}, i \in\{1,2\}$.

This is illustrated in the following figure.

\footnotetext{
${ }^{15}$ This amounts to taking a conservative stance on the 1924 US Supreme Court ruling in the case Texas Railroad Comm. v. Eastern Texas R.R. Co. which states that a regulatory agency cannot force a firm to provide a good or a service at a loss (see Spiegel and Spulber (1994)). As will become clear when asymmetric information is introduced, this does not mean that firms do not consider intertemporal profits in their decision making.

${ }^{16}$ This is the case when $\bar{\theta}<\mu \bar{q}_{i}$.
} 


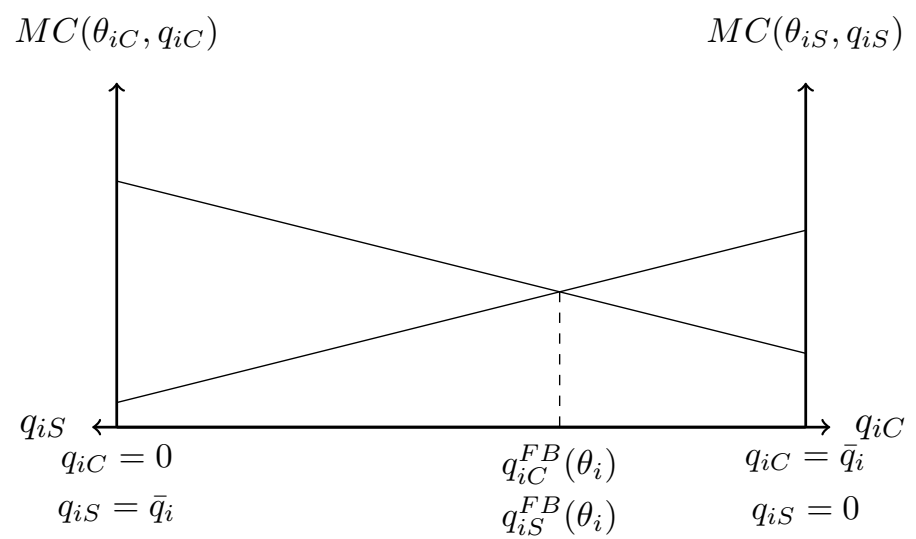

Figure 1: Optimal first-best provision rule $\left(\theta_{i S}>\theta_{i C}\right)$

If one firm is inherently more efficient than the other so that (2) does not have a solution in $\left[0, \bar{q}_{i}\right]$, then the optimal strategy for the procurement agency is to select sole sourcing from the most efficient firm. Since the focus of this paper is on the effect of financial constraints rather than the optimality of dual sourcing, in the sequel I will focus on the case where dual sourcing is optimal.17

Because total quantity in each period is fixed, there can be no distortion of this quantity. This paper therefore focuses on the allocative role of asymmetric information and financial structure on the distribution of quantities across firms.

\section{Benchmark: No financial constraints}

As a benchmark, assume that there are no financial constraints, but asymmetric information on costs. Applying the Revelation Principle (Myerson (1982), Myerson (1986)), a procurement contract is a long-term contract which stipulates transfers and quantities to both firms in each period. Each period's transfers $\left(t_{i C}, t_{i S}\right)$ and

\footnotetext{
${ }^{17}$ Although this paper presents a setting with convex costs $\grave{a}$ la Auriol and Laffont (1992) and McGuire and Riordan (1995) where dual sourcing is efficient, it is not a paper to motivate dual sourcing per se and the results would also go through in an auction model where the contract specifies each firm's probability of being awarded the project. In that case the two sides of (2) would be compared and the firm with the lowest marginal cost would provide $\bar{q}_{i}$.
} 
quantities $\left(q_{i C}, q_{i S}\right)$ are contingent on firms' announcements $\tilde{\theta}_{i k}$ in that period 18 Formally, the procurement contract can be written

$$
\left\{q_{1 C}\left(\tilde{\theta}_{1}\right), q_{1 S}\left(\tilde{\theta}_{1}\right), t_{1 C}\left(\tilde{\theta}_{1}\right), t_{1 S}\left(\tilde{\theta}_{1}\right),\left\{q_{2 C}\left(\tilde{\theta}_{2}\right), q_{2 S}\left(\tilde{\theta}_{2}\right), t_{2 C}\left(\tilde{\theta}_{2}\right), t_{2 S}\left(\tilde{\theta}_{2}\right)\right\}\right\} .
$$

The timing of the game is as follows:. The procurement agency commits to a longterm procurement contract. Firms then pay their fixed cost $D$ and, at the beginning of each period, types for this period are privately observed. Firms announce their type, and transfers and quantities according to the procurement contract take place. This is illustrated in the following timeline.

\begin{tabular}{|c|c|c|c|}
\hline Perio & d 0 & Period 1 & Period 2 \\
\hline $\begin{array}{l}\text { Procurement } \\
\text { Contract }\end{array}$ & $\begin{array}{c}\text { Firms pay } \\
D\end{array}$ & $\underset{\theta_{1}}{\operatorname{Learn}}\left(t_{1}, q_{1}\right)$ & $\begin{array}{c}\underset{\theta_{2}}{\operatorname{Learn}}\left(t_{2}, q_{2}\right) \\
\end{array}$ \\
\hline
\end{tabular}

Focusing on dominant strategy incentive compatibility 19 , the procurement agency's optimization problem can be formalized as

$$
\min _{\left(t_{i k}(\cdot), q_{i k}(\cdot)\right)_{i=1,2, k=C, S}} E_{\theta_{1}, \theta_{2}}\left[\sum_{i=1,2}\left(t_{i C}\left(\theta_{i}\right)+t_{i S}\left(\theta_{i}\right)\right)\right]
$$

subject to

$$
\begin{aligned}
& \Pi_{i k}\left(\theta_{i}\right) \equiv \pi_{i k}\left(\theta_{i k}, \theta_{i}\right) \equiv t_{i k}\left(\theta_{i}\right)-C\left(\theta_{i k}, q_{i k}\left(\theta_{i}\right)\right) \geq 0, \\
& \theta_{1 k} \in \arg \max _{\hat{\theta}_{1 k}}\left(\pi_{1 k}\left(\hat{\theta}_{1 k}, \theta_{1}\right)+E_{\theta_{2}}\left[\pi_{2 k}\left(\theta_{2}\right)\right]\right), \\
& \theta_{2 k} \in \arg \max _{\hat{\theta}_{2 k}} \pi_{2 k}\left(\hat{\theta}_{2 k}, \theta_{2}\right), \\
& q_{i S}\left(\theta_{i}\right)=\bar{q}_{i}-q_{i C}\left(\theta_{i}\right),
\end{aligned}
$$

\footnotetext{
${ }^{18}$ See footnote 14 .

${ }^{19}$ In these models, with only Bayesian incentive compatibility there is an infinity of solutions to the value of transfers of which one is also incentive compatible in dominant strategies. Requiring dominant strategies allows us to focus on one particular transfer. Pinning down the exact transfer function will be important when analyzing the effect of the financial contract.
} 
where $i \in\{1,2\},(k, j) \in\{C, S\}^{2}, k \neq j$.

The solution to the above optimization problem is characterized in the following proposition.

Proposition 1. Assume $\Delta \theta+\frac{1}{f_{k}(\theta)}<\mu \bar{q}_{i}, k \in\{C, S\}$. The optimal procurement contract when no firm is financially constrained is such that both firms produce at the same virtual marginal cost (see Muerson (1981)):

$$
V M C\left(\theta_{i C}, q_{i C}\left(\theta_{i}\right)\right)=V M C\left(\theta_{i S}, \bar{q}_{i}-q_{i C}\left(\theta_{i}\right)\right)
$$

where for $k \in\{C, S\}, i \in\{1,2\} V M C$ is defined as

$$
V M C\left(\theta_{i k}, q_{i k}\left(\theta_{i}\right)\right) \equiv \frac{\partial C\left(\theta_{i k}, q_{i k}\left(\theta_{i}\right)\right)}{\partial q_{i k}}+\frac{F_{k}}{f_{k}}\left(\theta_{i k}\right) .
$$

In each period, the solution to (3) is such that the virtual marginal cost of the cash-constrained firm for producing $q_{i C}\left(\theta_{i}\right)$ equals the virtual marginal cost of the self-financed firm for producing $q_{i S}\left(\theta_{i}\right)$. This is illustrated in the following figure (for equal cost distributions and where dashed lines represent marginal costs).

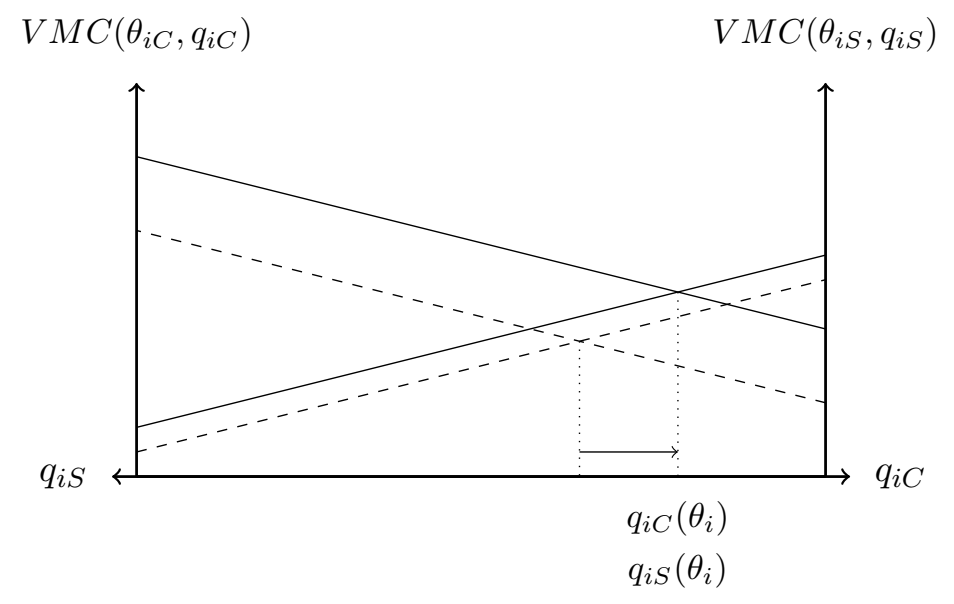

Figure 2: Optimal provision rule without financial constraints $\left(\theta_{i S}>\theta_{i C}\right)$ 
With only one firm and a fixed quantity to be procured, it is immediate to check that there is no possibility of getting the firm to truthfully reveal its cost and the firm's (monopoly) rents are high. The effect of having two firms is clearly that now the firm can be given incentives to reveal its costs and although an information rent has to be paid, this lowers expected costs for the principal.

Furthermore, when firms differ in their efficiency, the procurement agency will give more than half of the provision to the more efficient firm. Compared to the solution with complete information, under asymmetric information the share of production attributed to the more efficient firm is further increased by the information rent. By shifting an even larger part of the provision from the less efficient firm to the more efficient firm, the procurement agency minimizes the required information rent. Finally, the more the firms differ in their types $\theta_{i k}$, the more the quantities they are asked to provide differ. As in Myerson (1981), when types are drawn from different distributions, the optimal allocation rule might not be efficient. In other words, if $F_{C}(\cdot) \neq F_{S}(\cdot)$, then a low virtual marginal cost does not necessarily imply a low marginal cost (not illustrated in the figure above).

This proposition encompasses several results that are known from the literature. It shows that the dynamic contracting problem with independent cost reduces to two sequential static contracting problems and the results of Baron and Myerson (1982) and Auriol and Laffont (1992) still hold. It can also be seen as a multi-agent version of a particular case of Baron and Besanko (1984). Because of the convexity of costs, as in Auriol and Laffont (1992) it is not necessarily efficient to allocate the whole provision to only one firm. In the sequel the focus will be on how the financial structure of firms affects the procurement agency's provision rule, and how and when this rule differs from an ex ante symmetric treatment of firms as in (3). 


\section{Procurement with both self-financed and cash- constrained firms}

\subsection{Contracts and Timing}

This section focuses on the case where the procurement agency does not offer financial support 20 Firms that lack financial resources must therefore contract separately with their investors. Consequently, there are two distinct contracts that need to be characterized: the optimal procurement contract and the optimal financial contract.

As in previous sections a procurement contract is a long-term contract which stipulates transfers to both firms and the associated quantities to be produced by the two firms in each period. Formally, the procurement contract can be written as

$$
\left\{q_{1 C}\left(\tilde{\theta}_{1}\right), q_{1 S}\left(\tilde{\theta}_{1}\right), t_{1 C}\left(\tilde{\theta}_{1}\right), t_{1 S}\left(\tilde{\theta}_{1}\right),\left(q_{2 C}^{n}\left(\tilde{\theta}_{2}\right), q_{2 S}^{n}\left(\tilde{\theta}_{2}\right), t_{2 C}^{n}\left(\tilde{\theta}_{2}\right), t_{2 S}^{n}\left(\tilde{\theta}_{2}\right)\right)_{n=d, m}\right\}
$$

where $n$ describes whether both firms are still active in the second period (duopoly situation with superscript $d$ ) or whether the self-finance firm is in a monopoly situation (superscript $m$ ). $n$ is observable and verifiable between periods.21

A cash-constrained firm will have to finance its fixed costs by entering into a financial contract with an investor. Without asymmetric information, a financial contract between the investor and the cash-constrained firm would simply be a sharing rule of realized profits that covers the investor's investment cost. However, in reality, a financial contract generally includes a risk of punishment if the repayment is not sufficiently high. This possibility is allowed for by assuming that the financial contract cannot be directly contingent on the procurement contract and the outcome of the procurement contract is therefore non-contractible 22 Once a firm has realized

\footnotetext{
${ }^{20}$ See Section 4.4 for the case of state financing.

${ }^{21} \mathrm{~A}$ firm closing its doors and letting go of its employees is assumed to be a publicly observable event. While costs can be hidden from other players, bankruptcy is assumed to be a major event which in reality is likely to be talked about in the media and by the concerned employees and it is therefore not hidden information.

${ }^{22}$ See Bolton and Scharfstein (1990) for a list of reasons for contracts not being profit-contingent.
} 
its profits, it needs to be induced to repay the investor rather than to strategically default on its repayment. As in Bolton and Scharfstein (1990), Faure-Grimaud (1997) and Faure-Grimaud (2000), a financial contract therefore stipulates a repayment scheme for the first period, a non-liquidation probability as well as a repayment scheme for the second period. Formally, a financial contract is a menu

$$
\left\{R_{1}\left(\hat{\pi}_{1 C}\right),\left(R_{2}\left(\hat{\pi}_{1 C}, \hat{\pi}_{2 C}\right)\right), \beta\left(\hat{\pi}_{1 C}\right)\right\}
$$

where $R_{1}\left(\hat{\pi}_{1 C}\right)$ is the repayment in period 1 for a firm announcing profit level $\hat{\pi}_{1 C}$, $R_{2}\left(\hat{\pi}_{1 C}, \hat{\pi}_{2 C}\right)$ is the repayment in period 2 for a firm announcing profit level $\hat{\pi}_{1 C}$ in the first period and $\hat{\pi}_{2 C}$ in the second period, and, finally, $\beta\left(\hat{\pi}_{1 C}\right)$ is the probability of non-liquidation before the second period following the announcement $\hat{\pi}_{1 C} 23$ If a firm strategically defaults on its repayment in the first period, it can be punished by not being allowed to remain active in the second period 24

The timing of the game is summarized in the following figure.

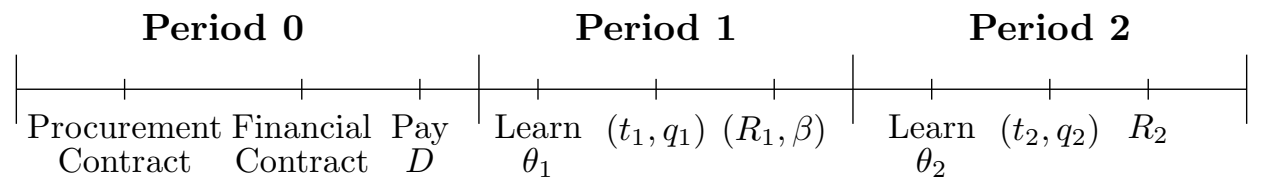

At the beginning of the game the procurement agency commits to a long-term procurement contract. Then the cash-constrained firm negotiates a financial contract with the investor and firms pay the fixed cost $D$. At the beginning of each of the two provision periods, active firms privately learn their type and privately announce their type to the procurement agency. Next the outcome of this period's procurement stage is realized. In order to honor its financial contract, an active cash-constrained firm

\footnotetext{
${ }^{23}$ Note that the only reason for which the investor would want information on the realization of the procurement contract and the cost parameter of the firm is because it allows him to deduce the profit level of the cash-constrained firm. Therefore instead of assuming that the financial contract depends on the firms' announcement of the procurement contract, a different approach is taken where the financial contract is contingent on the (announced) profit level of the cash-constrained firm.

${ }^{24} \mathrm{An}$ extension of the model where transfers and quantities from the procurement contract are contractible is studied in Subsection 4.4 .
} 
announces its realized profits to the investor and makes its repayment. At the end of the first period, the financial contract determines whether the cash-constrained firm is allowed to remain active or not.

Given the sequential nature of the timing, this paper characterizes the sub-game perfect equilibrium of this game.

\subsection{Optimal financial contract}

Since there is competition between investors, the optimal financial contract maximizes the firm's expected inter-temporal profit subject to the incentive compatibility, limited liability and investor's individual rationality constraints.

For ease of notation $\Pi_{2 C}^{d}$ denotes the cash-constrained firm's ex ante expected profit in the second-period procurement contract when both firms remain active. Since $\Pi_{1 C}\left(\theta_{1}\right)=t_{1 C}\left(\theta_{1}\right)-C\left(\theta_{1 C}, q_{1 C}\left(\theta_{1}\right)\right)$, we can define the cumulative distribution function of $\Pi_{1 C}$ as $G\left(\pi_{1 C}\right)=\operatorname{Prob}\left\{\Pi_{1 C}\left(\theta_{1}\right) \leq \pi_{1 C}\right\}$. The associated density function is $g\left(\pi_{1 C}\right)$. The support of $\Pi_{1 C}$ is $\left[\underline{\Pi}_{1 C}, \bar{\Pi}_{1 C}\right]$ where $\bar{\Pi}_{1 C}=\max \Pi_{1 C}\left(\theta_{1}\right)$ and $\underline{\Pi}_{1 C}=$ $\min \Pi_{1 C}\left(\theta_{1}\right)$. Both $\Pi_{1 C}$ and $\Pi_{2 C}^{d}$ are endogenous and will be determined by the procurement stage.

Formally, the optimization problem writes

$$
\max _{\left\{R_{1}(), R_{2}(), \beta()\right\}} \int_{0}^{\bar{\Pi}_{1 C}}\left[\Pi_{1 C}-R_{1}\left(\Pi_{1 C}\right)+\beta\left(\Pi_{1 C}\right)\left[\Pi_{2 C}^{d}-E_{\Pi_{2 C}}\left[R_{2}\left(\Pi_{1 C}, \Pi_{2 C}\right)\right]\right]\right] d G\left(\Pi_{1 C}\right)
$$

subject to

$$
\begin{aligned}
& R_{1}\left(\Pi_{1 C}\right) \leq \Pi_{1 C}, \\
& R_{2}\left(\Pi_{1 C}, \Pi_{2 C}\right) \leq \Pi_{1 C}-R_{1}\left(\Pi_{1 C}\right), \\
& \Pi_{1 C} \in \underset{\hat{\Pi}_{1 C}}{\left.\arg \max _{1 C}-R_{1}\left(\hat{\Pi}_{1 C}\right)+\beta\left(\hat{\Pi}_{1 C}\right)\left[\Pi_{2 C}^{d}-R_{2}\left(\hat{\Pi}_{1 C}\right)\right]\right],} \\
& \int_{0}^{\bar{\Pi}_{1 C}}\left[R_{1}\left(\Pi_{1 C}\right)+\beta\left(\Pi_{1 C}\right)\left(R_{2}\left(\Pi_{1 C}\right)-D\right)\right] d G\left(\Pi_{1 C}\right) \geq D .
\end{aligned}
$$


Notice that since the investor has no means of eliciting any information on $\Pi_{2} 25$, the second-period limited liability constraint in (6) needs to be true for all $\Pi_{2}$, i.e. the second-period repayment has to be independent of $\Pi_{2}$. Any positive value of $R_{2}\left(\Pi_{1}, \Pi_{2}\right)=R_{2}\left(\Pi_{1}\right)$ can therefore be shifted to the first-period repayment.

The solution to this optimization is summarized in the following proposition.

Proposition 2. (Faure-Grimaud (2000))

The optimal financial contract $\left\{R_{1}\left(\hat{\pi}_{1 C}\right), R_{2}\left(\hat{\pi}_{1 C}, \hat{\pi}_{2 C}\right), \beta\left(\hat{\pi}_{1 C}\right)\right\}$ takes the form of a debt contract with all $R_{2}($.$) normalized to zero. In other words,$

- If the firm makes high enough profits, it reimburses a fixed amount $\pi_{1 C}^{*}$ and is never liquidated.

$$
\forall \Pi_{1 C} \geq \pi_{1 C}^{*}, \beta\left(\Pi_{1 C}\right)=1 \text { and } R_{1}\left(\Pi_{1 C}\right)=\pi_{1 C}^{*}
$$

- If profits are not high enough, the firm has to repay all its profits and the probability of refinancing is less than one.

$$
\forall \Pi_{1 C} \leq \pi_{1 C}^{*}, \beta\left(\Pi_{1 C}\right)=1-\frac{\pi_{1 C}^{*}-\Pi_{1 C}}{\Pi_{2 C}^{d}}<1 \text { and } R_{1}\left(\Pi_{1 C}\right)=\Pi_{1 C}
$$

The fixed repayment is given by the following equation

$$
\pi_{1 C}^{*}-\int_{\underline{\Pi}_{1 C}}^{\pi_{1 C}^{*}} G\left(\pi_{1 C}\right) d \pi_{1 C}=D
$$

This proposition reproduces the result of Faure-Grimaud (2000) who show that the optimal financial contract takes the form of a debt contract. The optimal financial contract described in Proposition 2 holds for a given distribution of profits. In this paper, the difference compared to Faure-Grimaud (2000) is that profits, $\Pi_{1 C}$, are endogenous and are determined by the procurement contract.

\footnotetext{
${ }^{25}$ The firm always has an incentive to claim $\Pi_{2}=0$.
} 


\subsection{Optimal procurement contract}

This section characterizes the optimal procurement contract. Since bankruptcy is a public event, if in the second period only the self-financed firm is left on the market, it necessarily provides $\bar{q}_{2}$. In this case incentive compatibility and individual rationality imply that

$$
t_{2 S}^{m}=C\left(\bar{\theta}, \bar{q}_{2}\right)
$$

and therefore $\Pi_{2 S}^{m}\left(\theta_{2 S}\right)=\left(\bar{\theta}-\theta_{2 S}\right) \bar{q}_{2}$.

In the case where both firms remain active in the second period, individual rationality and incentive compatibility for $k \in\{C, S\}$ can be written as follows 26

$$
\begin{aligned}
\Pi_{2 k}\left(\theta_{2}\right) & \equiv \pi_{2 k}^{d}\left(\theta_{2 k}, \theta_{2}\right)=t_{2 k}\left(\theta_{2}\right)-C\left(\theta_{2 k}, q_{2 k}\left(\theta_{2}\right)\right) \geq 0, \\
\theta_{2 k} & \in \underset{\hat{\theta}_{2 k}}{\arg \max _{2 k}} \pi_{2 k}^{d}\left(\hat{\theta}_{2 k}, \theta_{2}\right) .
\end{aligned}
$$

Denote by $\Pi_{2 k}^{d} \equiv E_{\theta_{2}}\left[\Pi_{2 k}^{d}\left(\theta_{2}\right)\right]$ firm $k$ 's expected profits in the second period when the two firms remain active and by $\Pi_{2 S}^{m} \equiv E_{\theta_{2}}\left[\Pi_{2 S}^{m}\left(\theta_{2}\right)\right]$ the self-financed firm's expected profit when it is the only active firm.

For the cash-constrained firm, incentive compatibility in the first-period requires that $\forall \theta_{1}$,

$$
\theta_{1 C} \in \arg \max _{\hat{\theta}_{1 C}} \pi_{1 C}\left(\hat{\theta}_{1 C}, \theta_{1}\right)-R_{1}\left(\pi_{1 C}\left(\hat{\theta}_{1 C}, \theta_{1}\right)\right)+\beta\left(\pi_{1 C}\left(\hat{\theta}_{1 C}, \theta_{1}\right)\right) \Pi_{2 C}^{d}
$$

with $\pi_{1 k}\left(\hat{\theta}_{1 k}, \theta_{1}\right)=t_{1 k}\left(\hat{\theta}_{1 k}, \theta_{1 j}\right)-C\left(\theta_{1 k}, q_{1 k}\left(\hat{\theta}_{1 k}, \theta_{1 j}\right)\right), k \in\{C, S\}$.

The following lemma greatly simplifies the cash-constrained firm's first-period incentive-compatibility constraint.

Lemma 1. $\forall \theta_{1}$, the incentive-compatibility condition in (15) can be replaced by

$$
\theta_{1 C} \in \arg \max _{\hat{\theta}_{1 C}} \pi_{1 C}\left(\hat{\theta}_{1 C}, \theta_{1}\right) .
$$

\footnotetext{
${ }^{26}$ Because monopoly transfers and quantities are always fixed and only duopoly variables vary with $\theta_{2}$, superscript "d" is dropped on transfers and quantities.
} 
Because the financial contract is also incentive compatible, the indirect effect of the announcement $\theta_{1 C}$ in the procurement contract is zero. When the cashconstrained firm considers how its announcement of first-period costs influences its intertemporal profits, it only considers the direct effect of the announcement on firstperiod profits. The financial contract with its repayments and liquidation probability does not influence the cash-constrained firm's incentives in the procurement contract.

Incentive compatibility for the self-financed firm can be written as, $\forall \theta_{1}$,

$$
\theta_{1 S} \in \arg \max _{\hat{\theta}_{1 S}} \pi_{1 S}\left(\hat{\theta}_{1 S}, \theta_{1}\right)+\Pi_{2 S}^{m}-\beta\left(\pi_{1 C}\left(\theta_{1 C}, \hat{\theta}_{1 S}\right)\right)\left[\Pi_{2 S}^{m}-\Pi_{2 S}^{d}\right]
$$

The expected profit of the self-financed firm depends on the financial contract of the cash-constrained firm. If the self-financed firm understates its cost in the firstperiod, it decreases the profits of the cash-constrained firm since in this situation more production goes to the self-financed firm and thus less to the cash-constrained firm. This reduces the value of $\beta\left(\Pi_{1 C}\left(\theta_{1}\right)\right)$ and therefore understating $\theta_{1 S}$ may increase the self-financed firm's expected profit from the second-period because it increases the likelihood of the self-financed firm becoming a monopoly in the second period and thus expected second-period profits.

Even if there is no direct externality of the financial contract from the cashconstrained firm, there is an indirect externality from the self-financed firm who has an incentive to accept a lower transfer to undertake the project in order to increase the chances of having monopoly power in the second period. This will be of crucial importance for obtaining the properties of the procurement contract.

Finally, first-period individual rationally requires

$$
\Pi_{1 k}\left(\theta_{1}\right) \geq 0
$$

The procurement agency's optimization problem can be written as

$$
\min _{\left(t_{i k}(\cdot), q_{i k}(\cdot)\right)_{i=1,2, k=C, S}} E_{\theta_{1}, \theta_{2}}\left[\sum_{k=C, S}\left(t_{1 k}\left(\theta_{1}\right)+\beta\left(\Pi_{1 C}\left(\theta_{1}\right)\right) t_{2 k}\left(\theta_{2}\right)\right)+\left(1-\beta\left(\Pi_{1 C}\left(\theta_{1}\right)\right)\right) C\left(\bar{\theta}, \bar{q}_{2}\right)\right]
$$


subject to (12)-(14), (16)-(18) and $q_{i S}\left(\theta_{i}\right)=\bar{q}_{i}-q_{i C}\left(\theta_{i}\right), i \in\{1,2\}$.

The next two propositions characterize the solution to this optimization problem.

Proposition 3. When both firms remain active in the second period, then the secondperiod procurement $\left(q_{2 C}\left(\theta_{2}\right), q_{2 S}\left(\theta_{2}\right)\right)$ is given by

$$
M C\left(\theta_{2 C}, q_{2 C}\left(\theta_{2}\right)\right)+\frac{F_{C}}{f_{C}}\left(\theta_{2 C}\right)=M C\left(\theta_{2 S}, q_{2 S}\left(\theta_{2}\right)\right)+\frac{E_{\theta_{1 C}}\left[\beta\left(\Pi_{1 C}\left(\theta_{1 C}, \bar{\theta}\right)\right)\right]}{E_{\theta_{1}}\left[\beta\left(\Pi_{1 C}\left(\theta_{1}\right)\right)\right]} \frac{F_{S}}{f_{S}}\left(\theta_{2 S}\right) .
$$

The equation in Proposition 3 states that when both firms remain active in the second period, they produce at the same virtual marginal cost, except that the self-financed firm's informational rent is weighted by a value that is greater than one 27 This implies that when both firms remain active in the second period, the cash-constrained firm receives a higher share of the contract than when firms are symmetric in terms of financial constraints.

This is illustrated in the following figure (for equal cost distributions and where the dashed line represents $\left.V M C_{2 S}(\cdot)\right)$.

\footnotetext{
${ }^{27}$ In the appendix it can be seen that the second-order condition for incentive compatibility requires $q_{1 C}\left(\theta_{1}\right)$ to be decreasing in $\theta_{1 C}$. Since $q_{1 S}\left(\theta_{1}\right)=\bar{q}_{1}-q_{1 C}\left(\theta_{1}\right)$, this means that $q_{1 C}\left(\theta_{1}\right)$ is increasing in $\theta_{1 S}$. First-period profits $\Pi_{1 C}\left(\theta_{1}\right)=\int_{\theta_{1 C}}^{\bar{\theta}} q_{1 C}\left(s, \theta_{1 S}\right) d s$ are therefore such that $\Pi_{1 C}\left(\theta_{1 C}, \bar{\theta}\right) \geq \Pi_{1 C}\left(\theta_{1}\right), \forall \theta_{1}$. Finally, since $\beta(\cdot)$ is increasing in profits, it is straightforward to conclude that $\frac{E_{\theta_{1 C}}\left[\beta\left(\Pi_{1 C}\left(\theta_{1 C}, \bar{\theta}\right)\right)\right]}{E_{\theta_{1}}\left[\beta\left(\Pi_{1 C}\left(\theta_{1}\right)\right)\right]} \geq 1$ and therefore that the second-period rule shifts more of the provision to the cash-constrained firm than the rule in (3).
} 


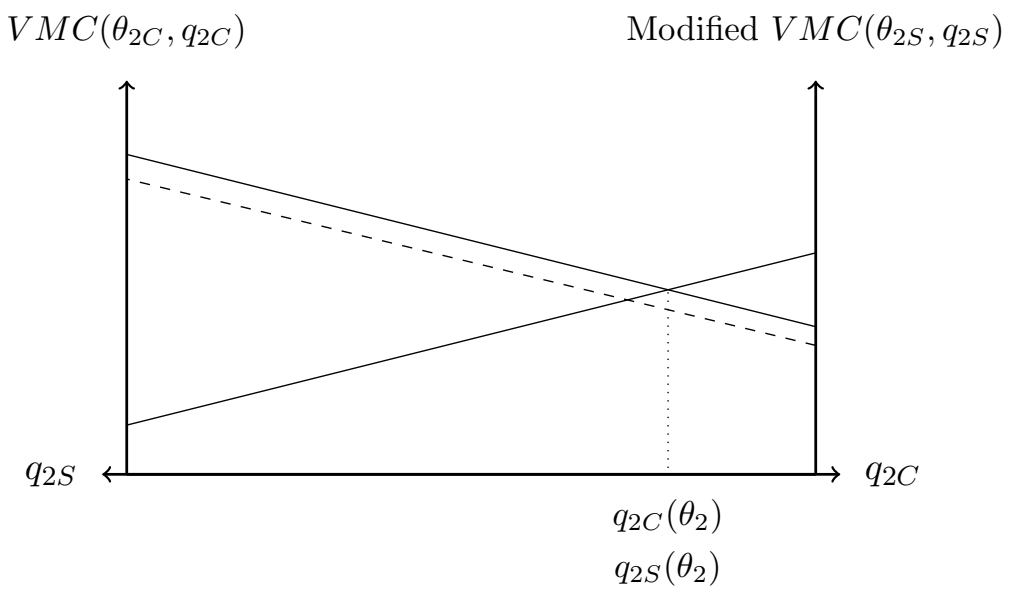

Figure 3: Optimal second-period provision rule $\left(\theta_{2 S}>\theta_{2 C}\right)$

So even though, in the second period, all active firms are symmetric in terms of (no) bankruptcy-risk, when taking into account the dynamic aspect of the procurement, a new reason for favoritism arises. First-period financial asymmetries carry over to the second-period in the form an asymmetric decision rule. In fact, favoring the cash-constrained firm in future procurement reduces the self-financed firm's expected future profits and therefore reduces the self-financed firm's required firstperiod payment. As shown in the next proposition, the first-period procurement contract reflects the trade-off between reduced first-period costs from giving the selffinanced firm incentives to push the weak player out of the market and increased future competition by favoring the financially weak player.

Proposition 4. The first-period procurement rule is characterized by the following equations:

- If $\theta_{1 C} \leq \theta_{1 C}^{*}\left(\theta_{1 S}\right)$ then the optimal quantity $q_{1 C}\left(\theta_{1}\right)$ satisfies:

$$
V M C\left(\theta_{1 S}, \bar{q}_{1}-q_{1 C}\left(\theta_{1}\right)\right)=V M C\left(\theta_{1 C}, q_{1 C}\left(\theta_{1}\right)\right) .
$$


- If $\theta_{1 C}>\theta_{1 C}^{*}\left(\theta_{1 S}\right)$ then the optimal quantity $q_{1 C}\left(\theta_{1}\right)$ satisfies:

$$
V M C\left(\theta_{1 S}, \bar{q}_{1}-q_{1 C}\left(\theta_{1}\right)\right)=V M C\left(\theta_{1 C}, q_{1 C}\left(\theta_{1}\right)\right)+\frac{1}{\Pi_{2 C}^{d}} \frac{F_{C}}{f_{C}}\left(\theta_{1 C}\right) P,
$$

where

$$
P \equiv E_{\theta_{2}}\left[\sum_{k=C, S} C\left(\theta_{2 k}, q_{2 k}\left(\theta_{2}\right)\right)+\frac{F_{C}}{f_{C}}\left(\theta_{2 C}\right) q_{2 C}\left(\theta_{2}\right)-C\left(\theta_{2 S}, \bar{q}_{2}\right)\right] .
$$

- If $\theta_{1 C}=\bar{\theta}$, then the optimal quantity $q_{1 C}\left(\theta_{1 C}, \bar{\theta}\right)$ satisfies

$$
V M C\left(\theta_{1 S}, \bar{q}_{1}-q_{1 C}\left(\theta_{1}\right)\right)=V M C\left(\theta_{1 C}, q_{1 C}\left(\theta_{1}\right)\right)+\frac{1}{\Pi_{2 C}^{d}} \frac{F}{f}\left(\theta_{1 C}\right) \tilde{P}
$$

where

$$
\tilde{P} \equiv P+E_{\theta_{2}}\left[\sum_{k=C, S}\left(C\left(\theta_{2 k}, q_{2 k}\left(\theta_{2}\right)\right)+\frac{F_{k}}{f_{k}}\left(\theta_{2 k}\right) q_{2 k}\left(\theta_{2}\right)\right)-C\left(\bar{\theta}, \bar{q}_{2}\right)\right] .
$$

First of all, notice that Proposition 4 states that if the cash-constrained firm is sufficiently efficient, then it is optimal offer the same unbiased procurement rule as in the case where firms are symmetric in their financial structure (Proposition 1).

However, when the cash-constrained firm is not sufficiently efficient compared to its competitor, there is a trade-off between reduced first-period costs by giving the self-financed firm incentives to push the weak player out of the market and increased competition by favoring the financially weak player. This trade-off can be subdivided into three effects:

- Sampling effect: Favor the cash-constrained firm to benefit from an increased probability of low provision costs in the second-period.

- Dual sourcing effect: Favor the cash-constrained firm to benefit from the possibility of dual sourcing in the future.

- Predation effect: Favor the self-financed firm to save on first-period transfers. 
Finally, because of the incentive-compatibility requirement of $q_{1 S}\left(\theta_{1}\right)$, it is shown in the appendix that $\theta_{1 S}=\bar{\theta}$ acts as a special case. The effects in the case above still apply, but by further favoring the cash-constrained firm, the first-period payment for all values of $\theta_{1 S}$ can be reduced.

The optimal first-period rule when $\theta_{1 C}>\theta_{1 C}^{*}\left(\theta_{1 S}\right)$ is illustrated in the following figure (where dashed lines represent $\left.V M C_{i C}(\cdot)\right)$.

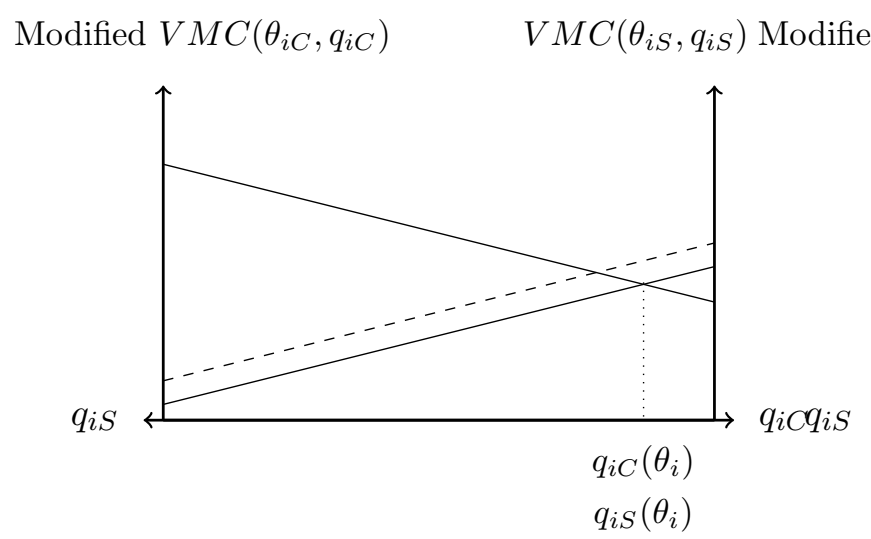

(a) $P<0$

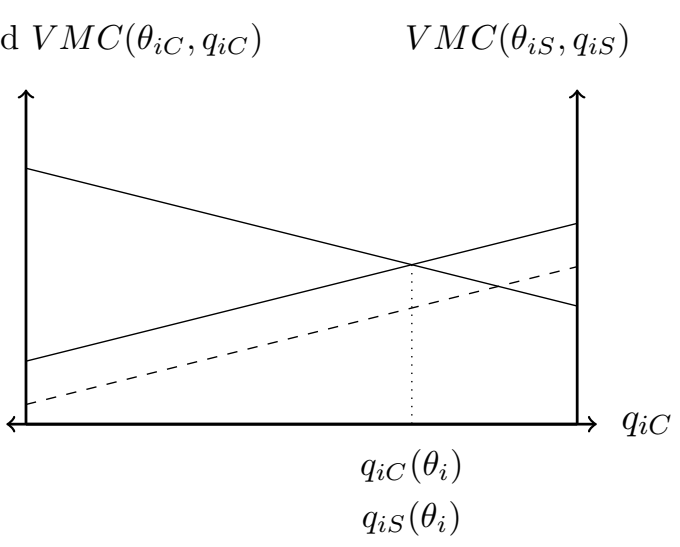

(b) $P>0$

Figure 4: Optimal first-period provision rule $\left(\theta_{1 C}>\theta_{1 C}^{*}\left(\theta_{1 S}\right)\right)$

Remark: This section has characterized the optimal financial contract and the optimal procurement contract. Furthermore, the next lemma states that at equilibrium, the debt contract is not such that the cash-constrained firm always repays a fixed amount. For high enough $\theta_{1 C}$, there will always be a non-zero risk of liquidation.

Corollary 1. $\exists \theta_{1}, \beta\left(\Pi_{1 C}\left(\theta_{1}\right)\right)<1$.

This implies that the bias in the first-period procurement is non-zero when the cash-constrained firm is relatively inefficient and thus the financial structure of firms matters for the design of the procurement contract. 


\subsection{Extensions and discussion}

\subsubsection{State financing}

Assume that the procurement agency can provide financial support to the cashconstrained firm. A contract offered by this integrated principal is then a mechanism that can be written as

$$
\left\{q_{1 C}\left(\tilde{\theta}_{1}\right), q_{1 S}\left(\tilde{\theta}_{1}\right), t_{1 C}\left(\tilde{\theta}_{1}\right), t_{1 S}\left(\tilde{\theta}_{1}\right), \beta\left(\tilde{\theta}_{1}\right),\left(q_{2 C}^{n}\left(\tilde{\theta}_{2}\right), q_{2 S}^{n}\left(\tilde{\theta}_{2}\right), t_{2 C}^{n}\left(\tilde{\theta}_{2}\right), t_{2 S}^{n}\left(\tilde{\theta}_{2}\right)\right)_{n=d, m}\right\},
$$

where $\left(t_{i}, q_{i}\right)$ are the transfers and quantities from the procurement contract for period $i$. In the second period transfers and quantities depend on whether both firms are still active (superscript $d$ ) or whether the self-finance firm is an a monopoly situation (superscript $m$ ). $\beta$ is the non-liquidation probability of the financially weak firm.

The timing of the game remains the same as in Section 3 except that since the procurement agency is also funding the participation of the cash-constrained firm, it can also make a decision regarding the liquidation of this firm 28 The timing is illustrated below.

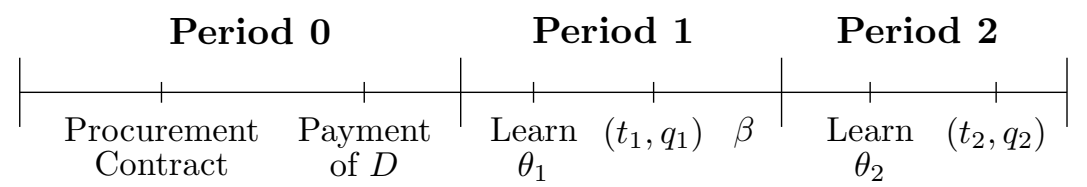

The analysis of the second-period constraints presented in Section 4.3 (resulting in the constraints given by (12)-(14)) still apply. First-period individual rationally

\footnotetext{
${ }^{28}$ This is somewhat artificial and could be replaced by putting second-period transfers and quantities equal to zero. However, to make the comparison to the main result simpler, the probability of non-liquidation $\beta(\cdot)$ is used.
} 
and incentive compatibility require that $\forall \theta_{1}, k \in\{C, S\}$

$$
\begin{aligned}
\Pi_{1 k}\left(\theta_{1}\right) & \geq 0, \\
\theta_{1 C} & \in \arg \max _{\hat{\theta}_{1 C}} \pi_{1 C}\left(\hat{\theta}_{1 C}, \theta_{1}\right)+\beta\left(\hat{\theta}_{1 C}, \theta_{1 S}\right) \Pi_{2 C}^{d}, \\
\theta_{1 S} & \in \arg \max _{\hat{\theta}_{1 S}} \pi_{1 S}\left(\hat{\theta}_{1 S}, \theta_{1}\right)-\beta\left(\theta_{1 C}, \hat{\theta}_{1 S}\right)\left(\Pi_{2 S}^{m}-\Pi_{2 S}^{d}\right)+\Pi_{2 S}^{m} .
\end{aligned}
$$

The procurement agency's optimization problem can be written as

$$
\min _{\left(t_{i k}(\cdot), q_{i k}(\cdot)\right)_{i=1,2, k=C, S}} E_{\theta_{1}, \theta_{2}}\left[\sum_{k=C, S}\left(t_{1 k}\left(\theta_{1}\right)+\beta\left(\theta_{1}\right) t_{2 k}^{d}\left(\theta_{2}\right)\right)+\left(1-\beta\left(\theta_{1}\right)\right) t_{2 S}^{m}\right]
$$

subject to (12)-(14), (25)-(27) and $q_{i S}\left(\theta_{i}\right)=\bar{q}_{i}-q_{i C}\left(\theta_{i}\right), i \in\{1,2\}$.

In the Appendix it is shown that the optimal procurement contract offered by the integrated principal has the following properties.

Proposition 5. Assume $\Delta \theta+\frac{1}{f_{k}(\theta)}<\mu \bar{q}_{i}, k \in\{C, S\}$. When the procurement agency can also provide financial support to the cash-constrained firm, then dual sourcing is optimal and the optimal procurement contract has the following characteristics:

- The cash-constrained firm is always refinanced: $\forall \theta_{1} \in \Theta^{2}, \beta\left(\theta_{1}\right)=1$.

- Both firms produce at the same virtual marginal cost as described in (3).

Proposition 5 shows that when one firm is financially constrained, then the cost of subsidizing $D$ for the cash-constrained firm without threatening it with bankruptcy, is outweighed by the gains from lower expected costs and increased future competition.

\subsubsection{Pre-bidding subsidies}

One question that has not yet been addressed is the optimality of a pre-bidding subsidy of (parts of) $D$ for both firms. Let $\tilde{D}$ be the total pre-bidding costs of each firm and denote by $\gamma$ the proportion of this cost that is subsidized by the procurement agency. With this notation, $D=(1-\gamma) \tilde{D}$. What proportion $\gamma$ of the pre-bidding cost should the procurement agency subsidize? In fact, when the procurement agency 
commits to a pre-bidding subsidy $\gamma \tilde{D}$, this has two effects on its expected costs. First, it has a direct effect in that it increases costs because the procurement agency has to pay $\gamma \tilde{D}$ to each firm. Second, it has an indirect effect that reduces second-period expected costs for the procurement agency. Since a subsidy decreases the share of the fixed cost that is borne by the firms, it reduces the amount that the cash-constrained firm needs to borrow. A lower loan implies a lower repayment, and the probability that the cash-constrained firm can reimburse and remain active in the second period increases 29 Without further restrictions on the environment, it is not possible to conclude which effect dominates. However, this would be an interesting question for future work, as it would link the current paper to Gal et al. (2007) who find that partially funding bidders' bid-preparation costs virtually always pays off. However, in contrast to Gal et al. (2007), the subsidy in this setting is constant across firms and it might be optimal to subsidize all or none of the pre-bidding costs.

\subsubsection{Contractibility}

In the previous analysis, an important assumption is that the financial contract cannot be directly contingent on the procurement contract. If both quantities and transfers are observed and made contractible, then the investor (and any outside agent) has enough information to deduce the realized value of $\theta_{1}$ and thus also to deduce the realized value of profits. As pointed out in Faure-Grimaud (1997) and Faure-Grimaud (2000), when there is no asymmetric information on realized profits, the optimal financial contract would simply stipulate a sharing rule of realized profits and there would be no need for (inefficient) bankruptcy risk. In this configuration, the optimal procurement contract is characterized by Proposition 1 ,

By simply making the procurement contract public (contractible) information, the procurement agency can ensure that financial constraints play no role and the optimal procurement contract reverts to the static second-best contract. In the case where the procurement agency cannot provide financial support to the cashconstrained firm, it can choose to either provide a pre-bidding subsidy to all firms or

\footnotetext{
${ }^{29}$ For technical details see the working paper version of this article.
} 
make the procurement contract public and contractible information. A pre-bidding subsidy is costly and might not even be profitable. However by making the procurement contract publicly verifiable information the procurement agency can at zero cost increase the efficiency of its contract and revert to a contract that implements the second-best.

\section{Conclusion}

This paper considers a setting where a procurement agency contracts with two potential providers, of which one is initially financially weak and relies on a financial contract with an investor. In particular, this paper shows that whenever a procurement agency cannot ex ante subsidize financially weak firms and when the procurement contract is not contractible information for the investor, then there is tension between the short-term gains from lower payments required by the self-financed firm and the long-term gains from competition. However, if possible, the procurement agency can overcome these difficulties by making the procurement contract public and contractible information.

On the more applied side, this paper can be seen as a contribution to the debate on whether policies such as the US Small Business Act that explicitly favors small firms are more desirable than policies such as the EU Principle of Equal Treatment. It shows that when procurement contracts are not observable or contractible to third parties and if financing the pre-bidding costs for small firms is not possible, then favoritism and biasing the procurement rules are appropriate tools. However, if institutions allow for it, fully financing pre-bidding costs for small firms is a superior policy. Or, the procurement agency can deter predation incentives and revert to the second-best optimal contract simply by making the procurement contract contractible information.

This paper focuses on the case of two firms, however the results can be made more general. As the number of firms increases, the biases decrease and tend to zero. However, as long as the number of firms remain sufficiently low, the results in this paper continue to hold. 
A related, albeit different question is how two procurement agencies (or firms) would allocate their contracts between two suppliers who both face a certain bankruptcy risk. The two procurement agencies can, through the quantities they allocate to each supplier, influence the suppliers' bankruptcy risk. Here, a new issue could potentially arise: free-riding between the two procurement agencies' "policy" or procurement rule.

\section{Acknowledgements}

I particularly thank my advisor David Martimort for his patience, help and suggestions. I have benefited from discussions with I. Alger, C. Argenton, B. Biais, G. Cheikbossian, T. Ellingsen, S. Goldlücke, C. Hellwig, E. Iossa, H. Karle, S. Kranz, Y. Lefouili, K. Mierendorff, R. Myerson, F. Rosar, W. Sand-Zantman, G. Spagnolo, S. Saussier, V. Valero and C. Wasser. I would also like to thank seminar participants at BI Norwegian Business School, SSE, TSE, ULB, the University of Mannheim, the University of Oslo and Université Paris 1 as well as participants at various conferences. I gratefully acknowledge financial support from the DFG (German Science Foundation) under SFB/TR-15. Previous versions of this paper were circulated under the title "Dynamic Procurement, Costly Bidding and Bankruptcy Risk".

\section{Appendix}

Proof of Proposition 1: The optimal procurement contract needs to satisfy the incentive constraints stated in the constraints of the optimization problem. As is standard in the contracting literature, the incentive constraint will be replaced by its first-order condition and the second-order condition will be ignored and checked ex post. The first- and second-order conditions are given in the following lemma.

Lemma 2. The procurement contract is incentive compatible if and only if

$$
\frac{\partial \Pi_{i k}\left(\theta_{i}\right)}{\partial \theta_{i k}}=-q_{i k}\left(\theta_{i}\right),
$$




$$
\frac{\partial q_{i k}(\cdot)}{\partial \theta_{i k}} \leq 0
$$

The proof of this lemma is standard and is therefore omitted 30 The problem where the second-order condition, (A.2), is ignored will be referred to as the relaxed problem.

Observe that (A.1) implies that profits are non-decreasing in $\theta_{i k}$, so that the participation constraint only binds for $\bar{\theta}$. Integrating (A.1) with respect to $\theta_{i k}$ yields

$$
\Pi_{i k}\left(\theta_{i}\right)=\int_{\theta_{i k}}^{\bar{\theta}} q_{i k}\left(s, \theta_{i j}\right) d s, \quad(k, j) \in\{C, S\}^{2}, k \neq j, i \in\{1,2\} .
$$

Replacing $t_{i k}\left(\theta_{i}\right)$ by $C\left(\theta_{i k}, q_{i k}\left(\theta_{i}\right)\right)+\Pi_{i k}\left(\theta_{i}\right)$ in the procurement agency's optimization problem and simplifying, yields the following expression for the procurement agency's relaxed problem.

$$
\min _{\left(q_{i C}(\cdot), q_{i S}(\cdot)\right)_{i=1,2}} E_{\theta_{1}, \theta_{2}}\left[\sum_{k=S, C} \sum_{i=1,2}\left(C\left(\theta_{i k}, q_{i k}\left(\theta_{i}\right)\right)+\frac{F_{k}}{f_{k}}\left(\theta_{i k}\right) q_{i k}\left(\theta_{i}\right)\right)\right]
$$

subject to $q_{i S}(\cdot)=\bar{q}_{i}-q_{i C}(\cdot), q_{i k}(\cdot) \geq 0$ and $q_{i k}(\cdot) \leq \bar{q}_{i}$ for $(k, j) \in\{C, S\}^{2}, k \neq j$ and $i=1,2$.

Ignoring the boundary conditions $q_{i k}(\cdot) \geq 0$ and $q_{i k}(\cdot) \leq \bar{q}_{i}$, the first-order condition yields the condition given in (3). It can be checked that (3) has a solution in $\left[0, \bar{q}_{i}\right]$ when $\Delta \theta+\frac{1}{f_{k}(\theta)}<\mu \bar{q}_{i}$.

Furthermore, the monotone hazard rate condition ensures that the second-order condition holds.

\section{Proof of Lemma 1:}

Incentive compatibility of the financial contract requires that $\forall \pi_{1 C},-R_{1}\left(\pi_{1 C}\right)+$ $\beta\left(\pi_{1 C}\right) \Pi_{2 C}^{d}=K$, where $K$ is some constant 31 Since this holds for every value of

\footnotetext{
${ }^{30}$ It can be found in the working paper version of this article.

${ }^{31}$ See proof of Result 1 in Faure-Grimaud (2000).
} 
$\pi_{1 C}$, it holds for $\pi_{1 C}\left(\theta_{1}\right), \forall \theta_{1}$. Incentive compatibility for the cash-constrained firm therefore reduces to

$$
\theta_{1 C} \in \arg \max _{\hat{\theta}_{1 C}} \pi_{1 C}\left(\hat{\theta}_{1 C}, \theta_{1}\right)+K .
$$

This is equivalent to the condition given in (16).

Proof of Propositions 3 and 4: As in previous proofs, nothing changes with regard to second-period individual rationality and incentive compatibility when both firms are still active and in the relaxed problem these constraints can be replaced by (A.3).

For the cash-constrained firm, Lemma 2 still applies and the participation constraint is binding for the least efficient type. Therefore, integrating the first-order condition and exploiting the participation constraint yields equation (A.3).

For the self-financed firm, the first-order condition is slightly more complicated:

$$
\frac{\partial\left[\Pi_{1 S}\left(\theta_{1}\right)+\beta\left(\Pi_{1 C}\left(\theta_{1}\right)\right)\left[\Pi_{2 S}^{d}-\Pi_{2 S}^{m}\right]\right]}{\partial \theta_{1 S}}=-q_{1 S}\left(\theta_{1}\right)
$$

The first-order condition is on the inter-temporal utility whereas the participation condition is on the per-period profit. To use the standard techniques of contract theory, I need to assume that the direct effect of the announcement $\hat{\theta}_{1 S}$ of first period profits dominates the indirect effect that works through the changes in the cash-constrained firm's non-liquidation probability. In other words, I assume that $\frac{\partial\left[\beta\left(\Pi_{1 C}\left(\theta_{1}\right)\right)\left[\Pi_{2 S}^{d}-\Pi_{2 S}^{m}\right]\right]}{\partial \theta_{1 S}}$ is small compared to $\frac{\partial\left[\Pi_{1 S}\left(\theta_{1}\right)\right]}{\partial \theta_{1 S}}$ so that the participation constraint is binding for the least efficient type and we can apply the same technique as for the cash-constrained firm's constraint to obtain the following expression for $\Pi_{1 S}\left(\theta_{1}\right) 32$

$$
\Pi_{1 S}\left(\theta_{1}\right)=\left(\beta\left(\Pi_{1 C}\left(\theta_{1 C}, \bar{\theta}\right)\right)-\beta\left(\Pi_{1 C}\left(\theta_{1}\right)\right)\right)\left(\Pi_{2 S}^{d}-\Pi_{2 S}^{m}\right)+\int_{\theta_{1 S}}^{\bar{\theta}} q_{1 S}\left(\theta_{1 C}, s\right) d s .
$$

\footnotetext{
${ }^{32}$ If this is not the case, then we are in a situation similar to Lewis and Sappington (1989) where the participation constraint binds for some interior type $\tilde{\theta}$. If that were the case here, then that would lead to further distortions of output (as in Lewis and Sappington (1989)). However, the additional biases presented in Propositions 3 and 4 still hold. This paper therefore abstracts from these further complications.
} 
From (A.6) it can be seen that the procurement agency has two instruments to reduce its first-period transfer to the self-financed firm: the split between $q_{1 C}\left(\theta_{1}\right)$ and $q_{1 S}\left(\theta_{1}\right)$ and the value of the second-period expected profit.

In the procurement agency's minimization problem, replacing transfers by the expression in (A.3) and (A.6) yields the following relaxed minimization problem.

$$
\begin{aligned}
\min _{\left(q_{i k}(\cdot)\right)_{k=C, S, i=1,2}} E_{\theta_{1}, \theta_{2}}[ & \sum_{k=C, S} V C\left(\theta_{1 k}, q_{1 k}\left(\theta_{1}\right)\right)+\beta\left(\Pi_{1 C}\left(\theta_{1}\right)\right)\left(\sum_{k=C, S} C\left(\theta_{2 k}, q_{2 k}\left(\theta_{2}\right)\right)\right. \\
& \left.+\frac{F}{f}\left(\theta_{2 C}\right) q_{2 C}\left(\theta_{2}\right)-C\left(\theta_{2 S}, \bar{q}_{2}\right)\right)+\beta\left(\Pi_{1 C}\left(\theta_{1 C}, \bar{\theta}\right)\right)\left(\frac{F}{f}\left(\theta_{2 S}\right) q_{2 S}\left(\theta_{2}\right)\right. \\
& \left.\left.-\left(\bar{\theta}-\theta_{2 S}\right) \bar{q}_{2}\right)\right]
\end{aligned}
$$

subject to $\bar{q}_{i}=q_{i C}\left(\theta_{i}\right)+q_{i S}\left(\theta_{i}\right), i \in\{1,2\}$.

Piecewise optimization with respect to $q_{2 C}\left(\theta_{2}\right)$ yields the rule stated in Proposition 3. Since $\frac{E_{\theta_{1 C}}\left[\beta\left(\Pi_{1 C}\left(\theta_{1 C}, \bar{\theta}\right)\right)\right]}{E_{\theta_{1}}\left[\beta\left(\Pi_{1 C}\left(\theta_{1}\right)\right)\right]}$ is a constant with respect to $\theta_{2}$ and because of the monotone hazard condition, the second-order conditions are still satisfied so that the solution to the relaxed problem is also the solution to the initial problem.

To see where the result in Proposition 4 comes from it is necessary to solve for the optimal first-period quantities of (A.7). To this aim, the following technical lemma will be helpful.

\section{Lemma 3.}

$$
E_{\theta_{1}}\left[\beta\left(\Pi_{1 C}\left(\theta_{1}\right)\right)\right]=1-\frac{\pi_{1 C}^{*}}{\Pi_{2 C}^{d}}+\frac{1}{\Pi_{2 C}^{d}} \int_{\underline{\theta}}^{\bar{\theta}} \int_{\theta_{1 C}^{*}\left(\theta_{1 S}\right)}^{\bar{\theta}} F_{C}\left(\theta_{1 C}\right) q_{1 C}\left(\theta_{1}\right) d \theta_{1 C} d F_{S}\left(\theta_{1 S}\right),
$$

where $\theta_{1 C}^{*}\left(\theta_{1 S}\right)$ is such that $\Pi_{1 C}\left(\theta_{1 C}^{*}\left(\theta_{1 S}\right), \theta_{1 S}\right)=\pi_{1 C}^{*}$ and $\pi_{1 C}^{*}$ is defined by (11).

Proof of Lemma 目:

By using (9) and (10), $E_{\theta_{1}}\left[\beta\left(\Pi_{1}\left(\theta_{1}\right)\right)\right]$ can be expressed as

$$
E_{\theta_{1}}\left[\beta\left(\Pi_{1}\left(\theta_{1}\right)\right)\right]=1-E_{\theta_{1 S}}\left[\int_{\theta_{1 C}^{*}\left(\theta_{1 S}\right)}^{\bar{\theta}} \frac{\pi_{1 C}^{*}-\Pi_{1 C}\left(\theta_{1}\right)}{\Pi_{2 C}^{d}} d F_{C}\left(\theta_{1 C}\right)\right],
$$


where $\theta_{1 C}^{*}\left(\theta_{1 S}\right)$ is such that $\Pi_{1 C}\left(\theta_{1 C}^{*}\left(\theta_{1 S}\right), \theta_{1 S}\right)=\pi_{1 C}^{*}$ and $\pi_{1 C}^{*}$ is defined by (11).

The distribution of $\theta_{1 C}^{*}\left(\theta_{1 S}\right)$ is for the specific distribution of profits that is given by the procurement contract. Since $\Pi_{1 C}\left(\theta_{1}\right)=\int_{\theta_{1 C}}^{\bar{\theta}} q_{1 C}\left(s, \theta_{1 S}\right) d s$ is a decreasing function of $\theta_{1 C}, G\left(\pi_{1 C}\right)$ can be rewritten as

$G\left(\pi_{1 C}\right)=\int_{\underline{\theta}}^{\bar{\theta}} \operatorname{Prob}\left\{\theta_{1 C} \geq \hat{\theta}_{1 C}\left(\theta_{1 S}, \pi_{1 C}\right)\right\} d F\left(\theta_{1 S}\right)=1-\int_{\underline{\theta}}^{\bar{\theta}} F_{C}\left(\hat{\theta}_{1 C}\left(\theta_{1 S}, \pi_{1 C}\right)\right) d F_{S}\left(\theta_{1 S}\right)$,

where $\hat{\theta}_{1 C}\left(\theta_{1 S}, \pi_{1 C}\right)$ is such that $\Pi_{1 C}\left(\hat{\theta}_{1 C}\left(\theta_{1 S}, \Pi_{1 C}\right), \theta_{1 S}\right)=\pi_{1 C}$.

Finally, when replacing $\Pi_{1 C}\left(\theta_{1}\right)$ by $\int_{\theta_{1 C}}^{\bar{\theta}} q_{1 C}\left(s, \theta_{1 S}\right) d s$ in (A.9) and integrating by part, the expected value of $\beta\left(\Pi_{1 C}\left(\theta_{1}\right)\right)$ can be expressed as (A.8).

Piecewise optimization of the regulatory agency's problem where $E_{\theta_{1}}\left[\beta\left(\Pi_{1 C}\left(\theta_{1}\right)\right)\right]$ has been replaced by $(A .8)$ yields the first-order conditions that are stated in Proposition 4 .

Now it only remains to verify that second-order conditions for the first-period quantities hold. For the self-financed firm, $\forall \theta_{1}, \frac{\partial q_{1 S}\left(\theta_{1}\right)}{\partial \theta_{1 S}}=\frac{-1}{2 \mu}\left(1+\frac{\partial \frac{F_{S}}{f_{S}}\left(\theta_{1 S}\right)}{\partial \theta_{1 S}}\right)<0$. And therefore, the second-order condition holds.

For the cash-constrained firm,

$$
q_{1 C}\left(\theta_{1}\right)=\frac{\bar{q}_{1}}{2}+\frac{\theta_{1 S}+\frac{F_{S}}{f_{S}}\left(\theta_{1 S}\right)-\theta_{1 C}-\frac{F_{C}}{f_{C}}\left(\theta_{1 C}\right)}{2 \mu}-\frac{P}{2 \mu \Pi_{2 C}^{d}} \frac{F_{C}}{f_{C}}\left(\theta_{1 C}\right),
$$

or the same expression without the last term if $\theta_{1 C} \leq \theta_{1 C}^{*}\left(\theta_{1 S}\right)$. For the exact expression of $P$ see Proposition 4. However, the important thing is that $P$ is constant with respect to $\theta_{1 C}$. This implies that,

$$
\frac{\partial q_{1 C}\left(\theta_{1}\right)}{\partial \theta_{1 C}}=-\frac{1}{2 \mu}\left(1+\frac{\partial \frac{F_{C}}{f_{C}}\left(\theta_{1 C}\right)}{\partial \theta_{1 C}}-\frac{P}{\Pi_{2 C}^{d}} \frac{\partial \frac{F_{C}}{f_{C}}\left(\theta_{1 C}\right)}{\partial \theta_{1 C}}\right)
$$

So, finally, the second-order condition for the cash-constrained firm holds if and only if the last term in (A.10) is not too positive.

Proof of Corollary 1; 
Suppose that the optimal financial debt contract is degenerate. In other words, $R_{1}\left(\Pi_{1 C}\right)=\pi_{1 C}^{*}$ and $\beta\left(\Pi_{1 C}\right)=1$ regardless of the realized profits of the firm. This implies that $\pi_{1 C}^{*} \leq \Pi_{1 C}\left(\bar{\theta}, \theta_{1 S}\right)=0$. However, this would violate individual rationality of the investor. Thus, the optimal financial contract is not degenerate.

\section{Proof of Proposition 5:}

Compared to the proof of Proposition 1, nothing changes with regard to secondperiod incentive compatibility when both firms are still active in the second period and in this case (A.3) remains valid.

First- and second-order conditions for first-period incentive compatibility are still given by Lemma 2, and integration by part (and using the fact that the highest type's participation constraint binds) yields the following expression for the cashconstrained firm's first-period expected profit.

$\Pi_{1 C}\left(\theta_{1}\right)+\beta\left(\theta_{1}\right) E_{\theta_{2}}\left[\frac{F_{C}}{f_{C}}\left(\theta_{2 C}\right) q_{2 C}\left(\theta_{2}\right)\right]=\int_{\theta_{1 C}}^{\bar{\theta}} q\left(s, \theta_{1 S}\right) d s+\beta\left(\bar{\theta}, \theta_{1 S}\right) E_{\theta_{2}}\left[\frac{F_{C}}{f_{C}}\left(\theta_{2 C}\right) q_{2 C}\left(\theta_{2}\right)\right]$.

Using the definition of $\Pi_{1 C}\left(\theta_{1}\right)$ and rearranging terms yields the following expression for the required first-period transfer

$$
\begin{array}{r}
t_{1 C}\left(\theta_{1}\right)=C\left(\theta_{1 C}, q_{1 C}\left(\theta_{1}\right)\right)+\int_{\theta_{1 C}}^{\bar{\theta}} q\left(s, \theta_{1 S}\right) d s-\beta\left(\theta_{1}\right) E_{\theta_{2}}\left[\frac{F_{C}}{f_{C}}\left(\theta_{2 C}\right) q_{2 C}\left(\theta_{2}\right)\right] \\
+\beta\left(\bar{\theta}, \theta_{1 S}\right) E_{\theta_{2}}\left[\frac{F_{C}}{f_{C}}\left(\theta_{2 C}\right) q_{2 C}\left(\theta_{2}\right)\right] .
\end{array}
$$

Similarly the self-financed firm's first-period transfer is

$$
\begin{array}{r}
t_{1 S}\left(\theta_{1}\right)=C\left(\theta_{1 S}, q_{1 S}\left(\theta_{1}\right)\right)+\int_{\theta_{1 S}}^{\bar{\theta}} q_{1 S}\left(s, \theta_{1 C}\right) d s-\beta\left(\theta_{1}\right) E_{\theta_{2}}\left[\frac{F_{S}}{f_{S}}\left(\theta_{2 S}\right) q_{2 S}\left(\theta_{2}\right)\right] \\
-\left(1-\beta\left(\theta_{1}\right)\right) E_{\theta_{2}}\left[\left(\bar{\theta}-\theta_{2 S}\right) \bar{q}_{2}\right]+\beta\left(\theta_{1 C}, \bar{\theta}\right) E_{\theta_{2}}\left[\frac{F_{S}}{f_{S}}\left(\theta_{2 S}\right) q_{2 S}\left(\theta_{2}\right)\right] \\
+\left(1-\beta\left(\theta_{1 C}, \bar{\theta}\right)\right) E_{\theta_{2}}\left[\left(\bar{\theta}-\theta_{2 S}\right) \bar{q}_{2}\right] .
\end{array}
$$

In fact, the refinancing variable $\beta(\cdot)$ modifies the continuation value for the firms 
in different ways and thus it also affects differently the transfers that they require to satisfy participation (and incentive) constraints in the initial procurement stage. The principal's relaxed problem is now to minimize, with respect to $\left(q_{i k}(\cdot)_{i \in\{1,2\}, k \in\{C, S\}}, \beta(\cdot)\right)$, the following expression

$$
\begin{aligned}
& E_{\theta_{1}, \theta_{2}}\left\{\sum_{k \in\{C, S\}}\left[C\left(\theta_{1 k}, q_{1 k}\left(\theta_{1}\right)\right)+\frac{F_{k}}{f_{k}}\left(\theta_{1 k}\right) q_{1 k}\left(\theta_{1}\right)+\beta\left(\theta_{1}\right)\left[C\left(\theta_{2 k}, q_{2 k}\left(\theta_{2}\right)\right)\right]\right]\right. \\
& -\beta\left(\bar{\theta}, \theta_{1 S}\right) \frac{F_{C}}{f_{C}}\left(\theta_{2 C}\right) q_{2 C}\left(\theta_{2}\right)+\beta\left(\theta_{1 C}, \bar{\theta}\right) \frac{F_{S}}{f_{S}}\left(\theta_{2 S}\right) q_{2 S}\left(\theta_{2}\right) \\
& \left.+\left(1-\beta\left(\theta_{1}\right)\right) C\left(\theta_{2 S}, \bar{q}_{2}\right)+\left(1-\beta\left(\theta_{1 C}, \bar{\theta}\right)\right)\left[\left(\bar{\theta}-\theta_{2 S}\right) \bar{q}_{2}\right]\right\} .
\end{aligned}
$$

The problem is linear in $\beta(\cdot)$ and the derivative of the objective function with respect to $\beta$ is proportional to $E_{\theta_{2}}\left[C\left(\theta_{2 C}, q_{2 C}\left(\theta_{2}\right)\right)+C\left(\theta_{2 S}, q_{2 S}\left(\theta_{2}\right)\right)-C\left(\theta_{2 S}, \bar{q}_{2}\right)\right]$. Having two firms draw second-period costs increases the chance of a low cost and this term is therefore negative. Notice also that when costs are strictly convex, the expected gain from having two active firms is positive and thus the term is negative. It is therefore optimal for the procurement agency to always subsidize the cash-constrained firm. Taking first-order conditions with respect to $q_{i k}(\cdot)$ yields the conditions of equality of marginal costs as in Proposition 11. Thanks to the monotone hazard rate condition, the second-order condition holds and the solution to the relaxed problem is also the solution to the initial problem.

\section{References}

Auriol, E. AND J.-J. LAfFont (1992), "Regulation by Duopoly", Journal of Economics and Management Strategy, vol. 1, $\mathrm{n}^{0}$ 3, 507-533.

Baron, D.P. And D. Besanko (1984), "Regulation and Information in a Continuing Relationship", Information Economics and Policy, vol. 1, 267-302.

Baron, D.P. and R.B. Myerson (1982), "Regulating a Monopolist with Unknown Costs", Econometrica, vol. 50, n ${ }^{4}$, 911-930. 
Berger, A. N. And G. F. Udell (2003), "Small Business and Debt Finance", Handbook of entrepreneurship research: An interdisciplinary survey and introduction, Kluwer Academic Publishers.

Bolton, P. and D.S. Scharfstein (1990), "A Theory of Predation Based on Agency Problems in Financial Contracting", The American Economic Review, vol. $80, \mathrm{n}^{0} 1,93-106$.

Branco, F. (1994), "Favoring Domestic Firms in Procurement Contracts", Journal of International Economics, vol. 37, 65-80.

Brander, J.A. And T.R. Lewis (1986), "Oligopoly and Financial Structure: The Limited Liability Effect", The American Economic Review, vol. 76, $\mathrm{n}^{0}$ 5, 956-970.

Faure-Grimaud, A. (1997), "The Regulation of Predatory Firms", Journal of Economics \& Management Strategy, vol. 6, $\mathrm{n}^{0}$ 1, 425-451.

Faure-Grimaud, A. (2000), "Product market competition and optimal debt contracts: The limited liability effect revisited", The European Economic Review, vol. $44, \mathrm{n}^{0} 10,1823-1840$.

Gal, S., M. Landsberger and A. Nemirovski (2007), "Participation in Auctions", Games and Economic Behavior, vol. 60, 75-103.

Lewis, T.R. And D.E.M. Sappington (1989), "Countervailing Incentives in Agency Problems", Journal of Economic Theory, vol. 49, 194-313.

Maskin, E. And J. Riley (2000), "Asymmetric Auctions", Review of Economics Studies, vol. 67, 413-438.

McAfee R.P. And J. McMillan (1989), "Government Procurement and International Trade", Journal of International Economics, vol. 26, 291-308.

McGuire T.G. And M.H. Riordan (1995), "Incomplete Information and Optimal Market Structure: Public Purchases From Private Providers", Journal of Public Economics, vol. 56, 125-141. 
Myerson, R.B. (1981), "Optimal Auction Design", Mathematics of Operational Research, vol. 6, $\mathrm{n}^{0} 1,58-73$.

Myerson, R. (1982), "Optimal Coordination Mechanisms in Generalized Principal-Agent Problems", Journal of Mathematical Economics, vol. 10, 67-81.

Myerson, R.B. (1986), "Multi-Stage Games with Communication", Econometrica, vol. 54, $\mathrm{n}^{0} 2,323-358$.

Rezende, L. (2009), "Biased Procurement Auctions", Economic Theory, vol. 38, 169-185.

Snyder, C. M.. (1996), "Negotiation and Renegotiation of Optimal Financial Contracts Under the Threat of Predation", The Journal of Industrial Economics, vol. $44, \mathrm{n}^{0} 3,325-343$.

Spiegel Y. And D.F. Spulber (1994), "The Capital Structure of a Regulated Firm", The RAND Journal of Economics, vol. 25, $\mathrm{n}^{0} 3,424-440$.

Spiegel Y. And D.F. Spulber (1997), "Capital Structure with Countervailing Incentives", The RAND Journal of Economics, vol. 28, $\mathrm{n}^{0}$ 1, 1-24.

Vagstad, S. (1995), "Promoting Competition in Public Procurement", Journal of Public Economics, vol. 58, 283-307. 